\title{
Obituario de la Dra. Gloria Garavito González Junio 25 de 1954-enero 4 de 2021, Bogotá
}

En el amanecer de este año y golpeados por el momento difícil por el que estamos pasando, nos sorprende una trágica noticia: nuestra colega y amiga entrañable, la Dra. Gloria Garavito, ha partido de una forma inesperada e intempestiva, posiblemente como ella deseaba cuando se refería a esto en sus conversaciones llenas de humor sobre la muerte, pero muy triste y sobrecogedora para todos los que la conocimos. Gloria fue una mujer excepcional, enfocada y asertiva, franca y sincera, una mente brillante, llena de respeto y tolerancia por sus semejantes, compartía con generosidad su conocimiento y opiniones con familiares, colegas, alumnos, pacientes y amigos; siempre adornada del buen humor que la caracterizaba, el cual hacía que aun en la discrepancia la conversación con ella resultara una experiencia exquisita.

Dra. Gloria Garavito (1954-2021).

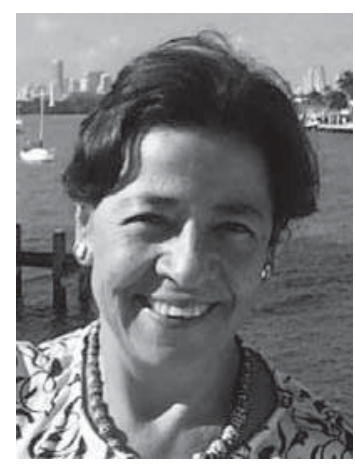

La Dra. Gloria Garavito se destacó en su carrera profesional desde sus inicios. En 1978 recibió su título de Doctora en Medicina en la Universidad Javeriana y en 1981 la misma universidad le otorgó el título de Especialista en Medicina Interna, luego de haber desarrollado su práctica clínica en el Hospital de la Samaritana. En 1983 viajó a París y trabajó en el Hospital Saint Antoine como asistente de endocrinología. En 1985 inició la residencia en endocrinología en el Hospital Militar Central de Bogotá y en 1990 trabajó como asistente de endocrinología en el Hammersmith Hospital, Royal Postgraduate Medical School, en Londres.

A su regreso a Colombia fue nombrada jefe de endocrinología del Instituto Nacional de Cancerología (INC), institución en la que permaneció hasta su retiro, en la que se destacó por su dedicación a la endocrinología oncológica. Durante todo este período, la labor docente la motivó e inspiró; los alumnos inquietos y reflexivos eran el motor para su continua actualización. Realmente lo disfrutaba.

En 1997 realizó una pasantía como asistente en endocrinología oncológica en el MD Anderson Cancer Center de Houston. En 2003, sin abandonar su trabajo en endocrinología oncológica, se interesó por incursionar en el área de la biología molecular en la Universidad de los Andes. Durante 1 año desarrolló un trabajo clínico que le mereció la distinción de tesis laureada y el título de Magíster en Biología Molecular; y en 2009 fue médica asistente en el servicio de endocrinología y manejo de patologías oncológicas en el Institut Clínic de Malalties Digestives i Metabòliques de Barcelona.

Además de pertenecer desde 1986 a nuestra Asociación como miembro de número, la Doctora Garavito también pertenecía a la Sociedad Latinoamericana de Neuroendocrinología como miembro fundador; a la Asociación Latinoamericana de Tiroides, como Miembro de Número; y a The Endocrine Society, como miembro activo desde marzo de 2012.

Recibió varias distinciones, entre ellas su tesis de grado laureada: "Anticuerpos antitiroglobulina como marcador de cáncer bien diferenciado de tiroides" en marzo de 2003 por la Universidad de Los Andes; La Mención honorífica: XIV Premio Aventis-Academia Nacional de Medicina, Área Clínica "Anticuerpos antitiroglobulina como marcador de cáncer de tiroides" en noviembre de 2003; y el reconocimiento institucional como profesor emérito del INC y Médico Especialista en Endocrinología Oncológica en noviembre de 2017. Realizó también un buen número de publicaciones a lo largo de su carrera profesional.

El vacío que deja la Dra. Gloria Garavito es muy grande porque es difícil encontrar una persona que reúna tantas cualidades y valores. La vamos a extrañar mucho sus familiares, sus colegas, sus pacientes y sus amigos. Gracias Gloria por el regalo de tu amistad, las vivencias compartidas y todo lo que de ti recibimos.

Henry Tovar, MD

Adriana Santamaría, MD

Stella Acosta, MD

Amanda Páez, MD 